\title{
The influence of source impedance on charge amplifiers
}

\author{
Henrik Volkers, Thomas Bruns \\ Physikalisch-Technische Bundesanstalt, Bundesallee 100, 38116 Braunschweig, Germany
}

\section{ABSTRACT}

This contribution discusses the influence of the source impedance on the complex sensitivity of a charge amplifier (CA). During calibration of a CA with varying source impedances, deviations at higher frequencies were observed, which if not properly taken into account may generate systematic errors beyond the limits of the measurement uncertainty budget. The contribution discusses a model to describe the effect as well as an extension to the CA calibration procedures which allow to quantify and correct the effect.

\section{Section: RESEARCH PAPER}

Keywords: charge amplifier, calibration

Citation: Henrik Volkers, Thomas Bruns, The influence of source impedance on charge amplifiers, Acta IMEKO, vol. 2, no. 2, article 10, December 2013, identifier: IMEKO-ACTA-02 (2013)-02-10

Editor: Paolo Carbone, University of Perugia

Received February $15^{\text {th }}, 2013$; In final form November $13^{\text {th }}, 2013$; Published December 2013

Copyright: @ 2013 IMEKO. This is an open-access article distributed under the terms of the Creative Commons Attribution 3.0 License, which permits unrestricted use, distribution, and reproduction in any medium, provided the original author and source are credited

Funding:This work has received funding from the European Union on the basis of Decision No 912/2009/EC

Corresponding author:Henrik Volkers, e-mail: henrik.volkers@ptb.de

\section{INTRODUCTION}

Since its invention in 1950 by Kistler [1], the calibration of charge amplifiers for piezoelectric sensors is usually performed with a setup similar to Figure 1. The sensor is replaced by a voltage source generating $u_{\mathrm{g}}$ and a standard capacitor of a well known value $C_{\mathrm{c}}$. By assuming $u_{\mathrm{i}}$ to be negligible, paralleled (cable) capacities $C_{\mathrm{p}}$ are ignored and the input charge is $q_{\mathrm{c}}=q_{\mathrm{i}}=u_{\mathrm{g}} \cdot C_{\mathrm{c}}$, resulting in the following formula for the complex transfer function:

$$
S_{\mathrm{uq}}(\omega)=\frac{u_{\mathrm{a}}}{u_{\mathrm{g}} C_{\mathrm{c}}}
$$

Calibrations at PTB and accredited laboratories of charge amplifiers performed with different standard capacitors $C_{\mathrm{c}}$ in a range from $10 \mathrm{pF}$ to $2000 \mathrm{pF}$ showed up significant systematic differences of $S_{\text {uq }}$ with increasing frequency. This led to the general conclusion that at higher frequencies, the burden voltage $u_{i}$ could no longer be ignored and the total source impedance of the sensor or calibration setup including cables as seen by the charge amplifier has to be regarded. While this effect is known for field measurements mainly caused by extended cable length capacity [2], the impact to laboratory calibrations had been overseen and has led to the following investigation.

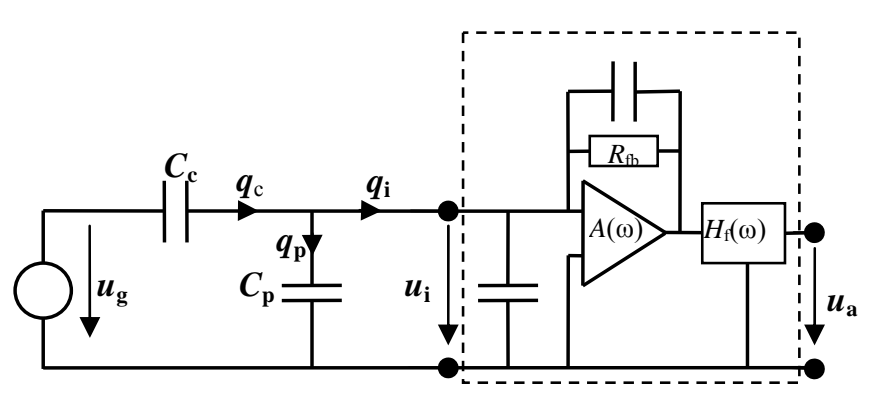

Figure 1. Schematic of a charge amplifier calibration setup.

\section{MEASURED DEVIATIONS}

The sensitivity $S_{\text {uq }}$ of six laboratory grade charge amplifiers of different types were measured with varying source impedances. For these amplifiers, Figure 2 shows the relative amplitude and absolute phase deviation taking a calibration with a $100 \mathrm{pF}$ standard capacitor as a reference and sourcing with an impedance of $1920 \mathrm{pF}$, quite well representing an Endevco Type 2270 transducer including the connecting cable. By using a $1000 \mathrm{pF}$ standard capacitor for calibration, this systematic deviation still will be about halved. 

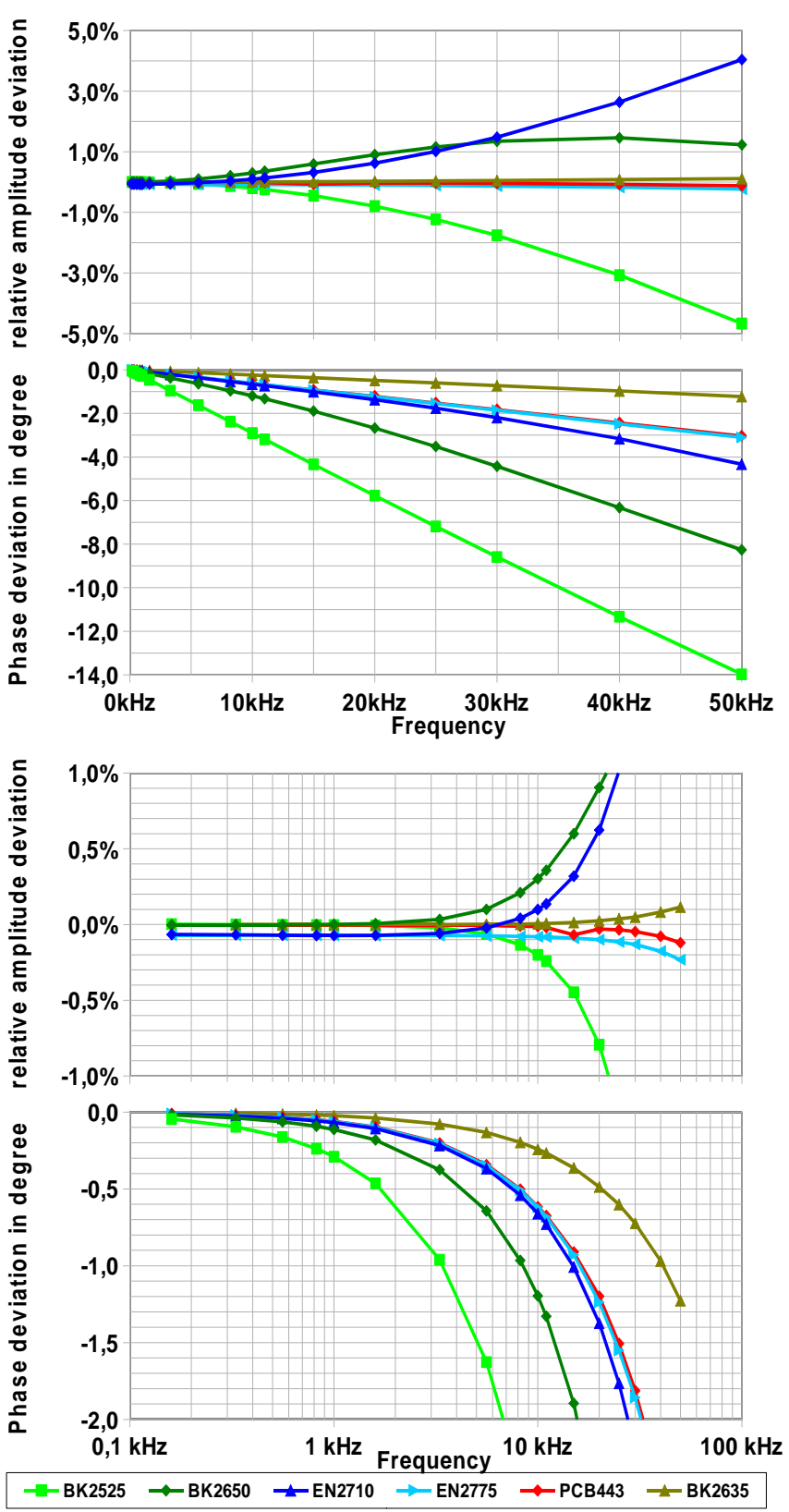

Figure 2. Systematic relative amplitude error and absolute phase error of the sensitivity $S_{\mathrm{uq}}(\omega)$ for different charge amplifiers if calibrated with $C_{\text {sCal }}=100 \mathrm{pF}+120 \mathrm{pF}$ and sourced with an impedance of $C_{\text {ssen }}=1920 \mathrm{pF}$. The two lower graphs show the same data with different scaling. The legend indicates brand and type of the investigated CA, however the results represent individual devices and might not be generally representative for these types of CAs.

The sensitivity to the source impedance of a CA is mainly determined by the first amplifier stage, its feedback network and the surrounding input protection circuit.

\section{MODELING THE CHARGE AMPLIFIER}

For further analyses the charge amplifier with its unknown circuit details is regarded as a black box with a complex, frequency dependent input impedance $Z_{\mathrm{i}}(\omega)$ and charge coupled base sensitivity $S_{0}(\omega)$ as shown in Figure 3.

$S_{0}(\omega)$ can be interpreted as the transfer function of the charge amplifier when driven by an ideal charge source.

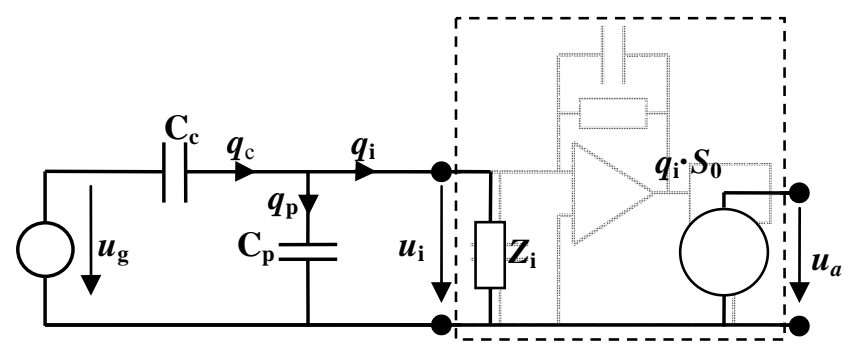

Figure 3. Simplified charge amplifier model.

The output voltage is

$u_{\mathrm{a}}=S_{\mathrm{o}}(\omega) \cdot q_{\mathrm{i}}$

and the input burden voltage

$u_{\mathrm{i}}=Z_{\mathrm{i}}(\omega) \cdot \dot{q}_{\mathrm{i}}=\mathrm{j} \omega \cdot Z_{\mathrm{i}}(\omega) \cdot q_{\mathrm{i}}$

for $q_{\mathrm{i}}=\hat{q}_{\mathrm{i}} \cdot e^{\mathrm{j} \omega t+\varphi_{\mathrm{i}}}$,

Kirchhoff's laws leads to

$$
\begin{aligned}
& q_{\mathrm{c}}=q_{\mathrm{i}}+q_{\mathrm{p}}, \\
& q_{\mathrm{c}}=\left(u_{\mathrm{g}}-u_{\mathrm{i}}\right) C_{\mathrm{c}}, \\
& q_{\mathrm{p}}=u_{\mathrm{i}} C_{\mathrm{p}}, \\
& \text { with (5), }(6) \text { in (4): } \\
& q_{\mathrm{i}}=u_{\mathrm{g}} C_{\mathrm{c}}-u_{\mathrm{i}}\left(C_{\mathrm{c}}+C_{\mathrm{p}}\right) .
\end{aligned}
$$

From the "traditional" calibration equation (1) we know:

$$
u_{\mathrm{g}} C_{\mathrm{c}}=\frac{u_{\mathrm{a}}}{S_{\mathrm{uq}}(\omega)} \text {. }
$$

With the total source impedance $C_{\mathrm{s}}=C_{\mathrm{c}}+C_{\mathrm{p}}$ and including (2), (3) and (8) in (7) this results in

$$
S_{\mathrm{uq}}(\omega)=\frac{S_{0}(\omega)}{1+Z_{\mathrm{i}}(\omega) \cdot \mathrm{j} \omega C_{\mathrm{s}}} .
$$

For an ideal charge amplifier with an input impedance of $Z_{i}=0 \Omega$, the source impedance $C_{\mathrm{s}}$ would have no influence on the resulting sensitivity $S_{\text {uq. }}$. One important conclusion from (9) is that for different calibrations or sensor setups with equal total source impedance $C_{\mathrm{s}}$, the resulting transfer functions $S_{\text {uq }}$ will be equal, too. For a given sensor cable impedance a charge amplifier calibration setup can be matched by adding an appropriate $C_{\mathrm{p}}$ for a given (smaller) calibration capacitor $C_{\mathrm{c}}$.

\section{COMPENSATION RESULTS}

To determine the characteristic values of the base sensitivity $S_{0}(\omega)$ and input impedance $Z_{\mathrm{i}}(\omega)$ of a charge amplifier, formula (9) is rewritten in the form

$$
\frac{1}{S_{\text {uq }}(\omega)}=\frac{1}{S_{0}(\omega)}+\mathrm{j} \omega \cdot \frac{Z_{\mathrm{i}}(\omega)}{S_{0}(\omega)} \cdot C_{\mathrm{s}},
$$

which allows a linear complex fit for the measured $S_{\text {uq }}$ with varying $C_{\mathrm{s}}$.

$C_{\mathrm{s}}$ was composed of three different calibrated standard capacitors $C_{\mathrm{c} 1,2,3}$ of $10 \mathrm{pF}, 100 \mathrm{pF}$ and $1000 \mathrm{pF}$ (GenRad Type 1404-A,B,C) and a variable capacitor GenRad Type 1422-D connected in parallel to the cable providing an adjustable capacitance $C_{\mathrm{p}}$ in the range of about $270 \mathrm{pF}$ to $1400 \mathrm{pF}$. The resulting total source impedance was measured by shortcutting $u_{\mathrm{g}}$ and measuring $C_{\mathrm{s}}$ at the connector to the amplifier using an HP4274A LCR meter.

$S_{\text {uq }}$ was measured using a PXI-System with an NI-PXI 5422 16 bit signal generator applying sine signals and a two channel NI-PXI-5922 24 bit digitizer with an NI-PXI-5900 differential 
preamplifier to simultaneously capture $u_{\mathrm{g}}$ and $u_{\mathrm{a}}$. Each measurement was taken twice with swapped input channels to cancel differences in the channel amplification and group delay. The major remaining uncertainties in this setup are the nonlinearities of the PXI-5922/5900 at a single frequency for ratio measurements $u\left(u_{a} / u_{g}\right)<60 \mathrm{ppm}$ ([3],[4]), the uncertainty of the standard capacitors $u\left(C_{\mathrm{c} 1}\right)<50 \mathrm{ppm}, u\left(C_{\mathrm{c} 2,3}\right)<20 \mathrm{ppm}$ and the charge amplifier noise. The overall expanded uncertainty is estimated to be less than $200 \mathrm{ppm}$. The uncertainty of the total source impedance measurement $u\left(C_{\mathrm{s}}\right)$ is less critical and the impact to the sensitivity uncertainty is about 2 orders smaller than $u\left(C_{\mathrm{c}}\right)$. An uncertainty of $u\left(C_{\mathrm{s}}\right) \leq 0.5 \%$ is still sufficient for an $U\left(S_{\text {uq }}\right) \leq 200 \mathrm{ppm}$.

For each frequency, the reciprocal measured complex $S_{\text {uq }}$ is split into a real and an imaginary part and a linear least square fit with the total source impedance $C_{\mathrm{s}}$ as the independent variable was applied. Figure 4 shows the reciprocal real and imaginary parts of $S_{\text {uq }}(\omega)$ for one single amplifier. Each line represents 8 measurements at one frequency. The relative mean squared errors of the fits are smaller than $10^{-5}$ indicating the validity of the proposed model.

Two transfer functions $S_{\text {uq }}(\omega)$ were measured with nearly the same total source impedance of $C_{\mathrm{s}}=1300 \mathrm{pF}$, but one used the $C_{\mathrm{c} 1}=10 \mathrm{pF}$ and the second used the $C_{\mathrm{c} 3}=1000 \mathrm{pF}$. Figure 5 shows the resulting $S_{\text {uq }}$ differences of the amplifier most sensitive to source impedance variations. The increase to $50 \mathrm{kHz}$ indicates a slight mismatch of $C_{\mathrm{s}}$ of about $3 \mathrm{pF}$. For the BK2635 and PCB443 amplifiers, no differences larger than the standard deviation of the measurements $\left(s \leq 5 \cdot 10^{-5}\right)$ were observed and are another proof of equation (9).

The amplitude and phase of the complex input impedance $Z_{i}(\omega)$ in $\Omega$ for the CAs investigated are shown in Figure 6. While the ideal charge amplifier would have an input impedance of $Z_{\mathrm{i}}=0 \Omega$, the real-world amplifiers investigated have input impedances ranging from $45 \Omega$ up to $500 \Omega$.

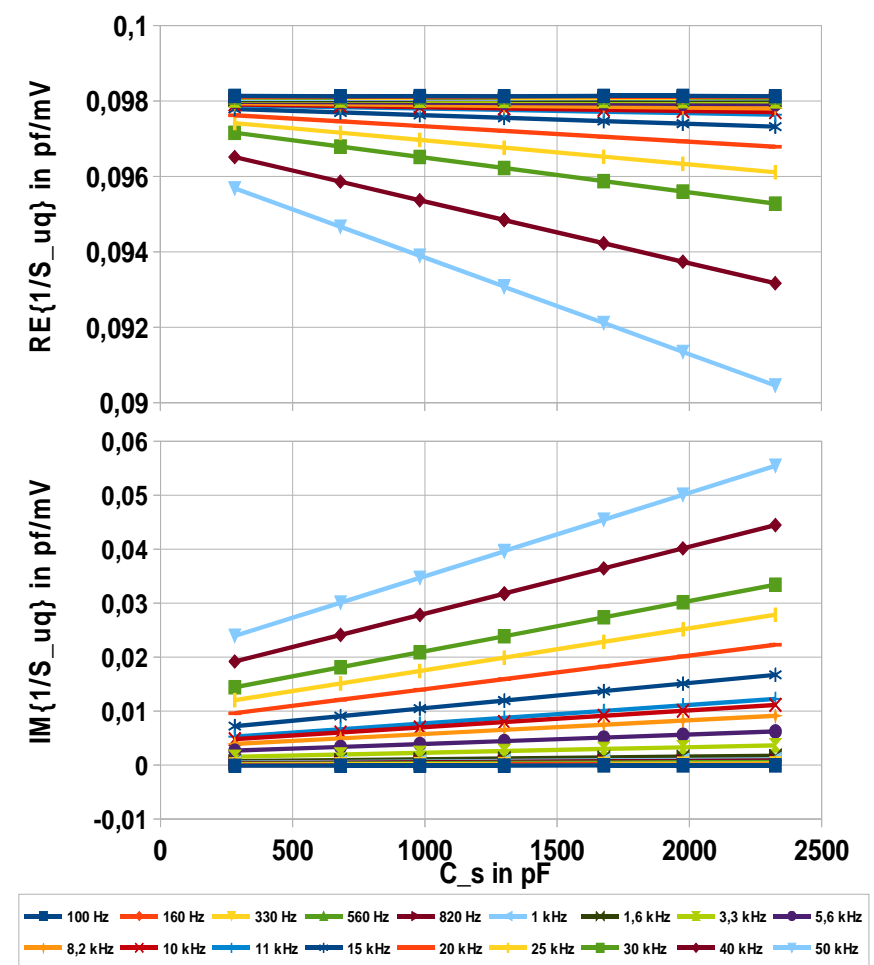

Figure 4. The real and imaginary inverse of $S_{u q}(\omega)$ for various source impedances Cs.

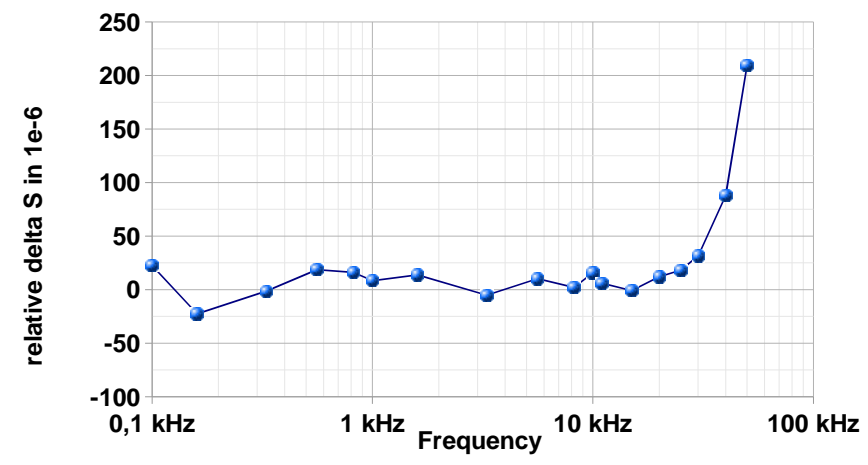

Figure 5. Deviation of two calibrations with $C_{\mathrm{c} 1}=10 \mathrm{pF}$ and $C_{\mathrm{c} 3}=1000 \mathrm{pF}$ where the total source impedance is matched to $C_{\mathrm{s}}=1300(3) \mathrm{pF}$.

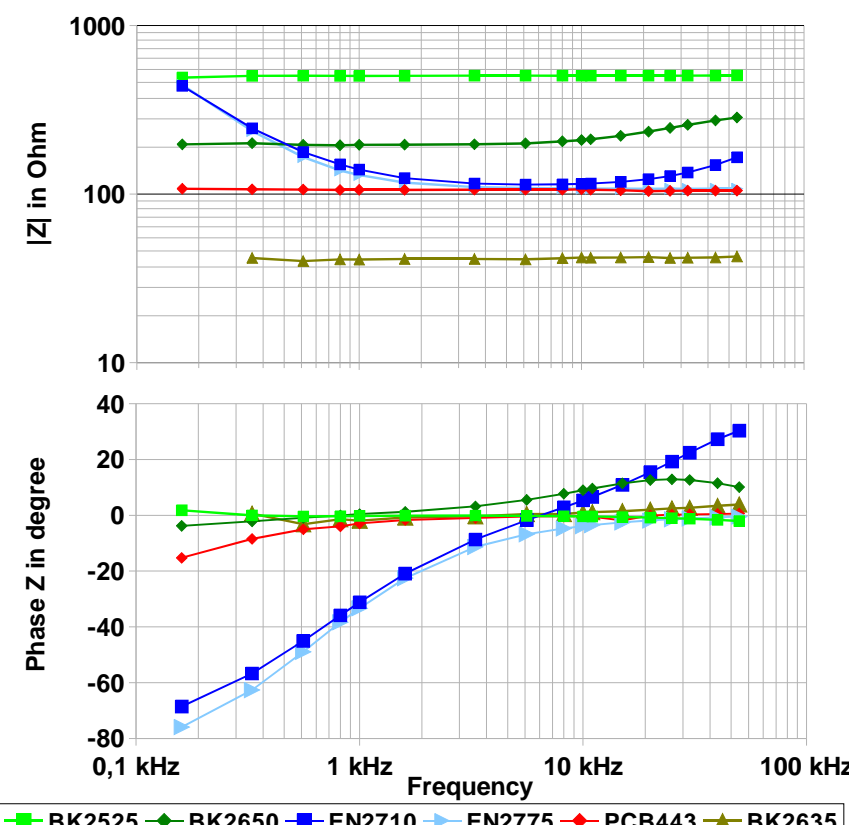

Figure 6 . Amplitude and phase of the complex input impedance $Z_{i}(\omega)$ of six different charge amplifiers.

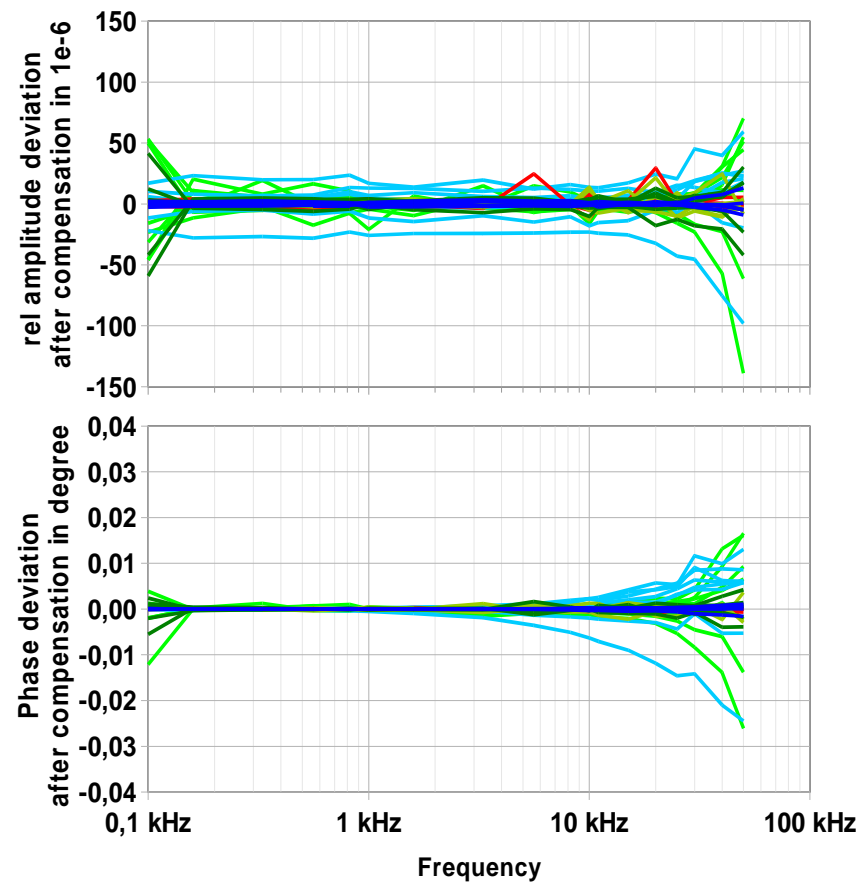

Figure 7. Amplitude and phase deviations of $S_{\mathrm{uq}}(\omega)$ after compensation, all CAs investigated, $280 \mathrm{pF} \leq C_{\mathrm{s}} \leq 2300 \mathrm{pF}$. 
With $S_{0}(\omega), Z_{\mathrm{i}}(\omega)$ and the known source impedance, the influence of the source impedance to the transfer function $S_{u q}(\omega)$ can be compensated by applying formula (9). Figure 7 shows the remaining deviations after compensation of all 6 CAs with source impedances from $280 \mathrm{pF}$ to $2300 \mathrm{pF}$ in a frequency range from $100 \mathrm{~Hz}$ to $50 \mathrm{kHz}, 648$ measurements in total. The values underlay the conservative estimation of a $U\left(S_{u q}(\omega)\right)<2 \cdot 10^{-4}$.

\section{IMPACT ON SENSOR CALIBRATION}

To validate the model approach of the charge amplifier for sensor calibration, we measured an Endevco 2270 BB accelerometer on a SE09 shaker with four different CAs.

The acceleration was measured with two heterodyne interferometers. Acceleration, output voltage amplitude and phase were determined by applying a sine approximation method (method 3 in ISO 16063-11). The frequency ranged from $100 \mathrm{~Hz}$ to $40 \mathrm{kHz}$ at an acceleration amplitude of $\hat{a}=100 \mathrm{~m} / \mathrm{s}^{2}$. The accelerometer mounting and the interferometer alignments were only performed once at the beginning of the measurement campaign. The only variable was the exchange of the charge amplifiers.

The four CAs were calibrated with source impedances built of a $C_{\mathrm{C}}=100 \mathrm{pF}$ and four $C_{\mathrm{P}}=\{148,806,1585,2143\} \mathrm{pF}$ to determine $Z_{\mathrm{i}}$ and $S_{0}$. The transfer functions $S_{\mathrm{uq}}(\omega)$ were then calculated according to formula (9) for a total source capacity of $C_{\text {ssen }}=1740(2) \mathrm{pF}$ measured at $10 \mathrm{kHz}$ with $1 \mathrm{~V}$ excitation.

The complex mean of all four measured sensor sensitivities $S_{\mathrm{qa} 1,2,3,4}(\omega)$ was taken as the reference and Figure 8 shows the resulting deviations. In addition, Figure 9 shows the systematic deviations that would occur without compensation and a 'common' $C_{\mathrm{C}}=100 \mathrm{pF}$ charge amplifier calibration. At higher frequencies this systematic deviation, if not properly taken into account, may exceed the limits of the measurement uncertainty budget. Note the different scaling in the vertical axes.

The uncertainties marked are determined as follows:

$$
\begin{aligned}
& U_{x}=k \sqrt{u_{0 x}{ }^{2}+\left(u_{1 x} \omega\right)^{2}+\left(u_{2 x} \omega^{2}\right)^{2}+s_{x}{ }^{2}}, \\
& u_{0 \hat{a}}=3.62 \times 10^{-4}, u_{1 \hat{a}}=2.23 \times 10^{-9}, u_{2 \hat{a}}=2.39 \times 10^{-13}, \\
& u_{0 \mathrm{P}}=2.10 \times 10^{-2}, u_{1 \mathrm{P}}=3.18 \times 10^{-7}, u_{2 \mathrm{P}}=1.91 \times 10^{-11},
\end{aligned}
$$

coverage factor $k=2$ and the standard deviation $s_{\mathrm{x}}$ of the measurement.

\section{CONCLUSIONS}

The influence of source impedance on charge amplifiers can be measured and explained with high confidence by the model shown in Figure 3 and the methods proposed.

By characterising the charge amplifier with its base sensitivity $S_{0}(\omega)$ and input impedance $Z_{i}(\omega)$ it is now possible to compensate this influence.

For calibrations of charged-based sensors with lowest possible uncertainty, the charge amplifier as the key linking element to the data acquisition system is usually calibrated before and after the sensor calibration. To avoid systematic deviations, these charge amplifier calibrations should be performed with a source impedance matching the sensor impedance. Now, this procedure has become a common practice in our laboratory at PTB.

\section{ACKNOWLEDGEMENT}

The research leading to these results has received funding from the European Union on the basis of Decision No 912/2009/EC.

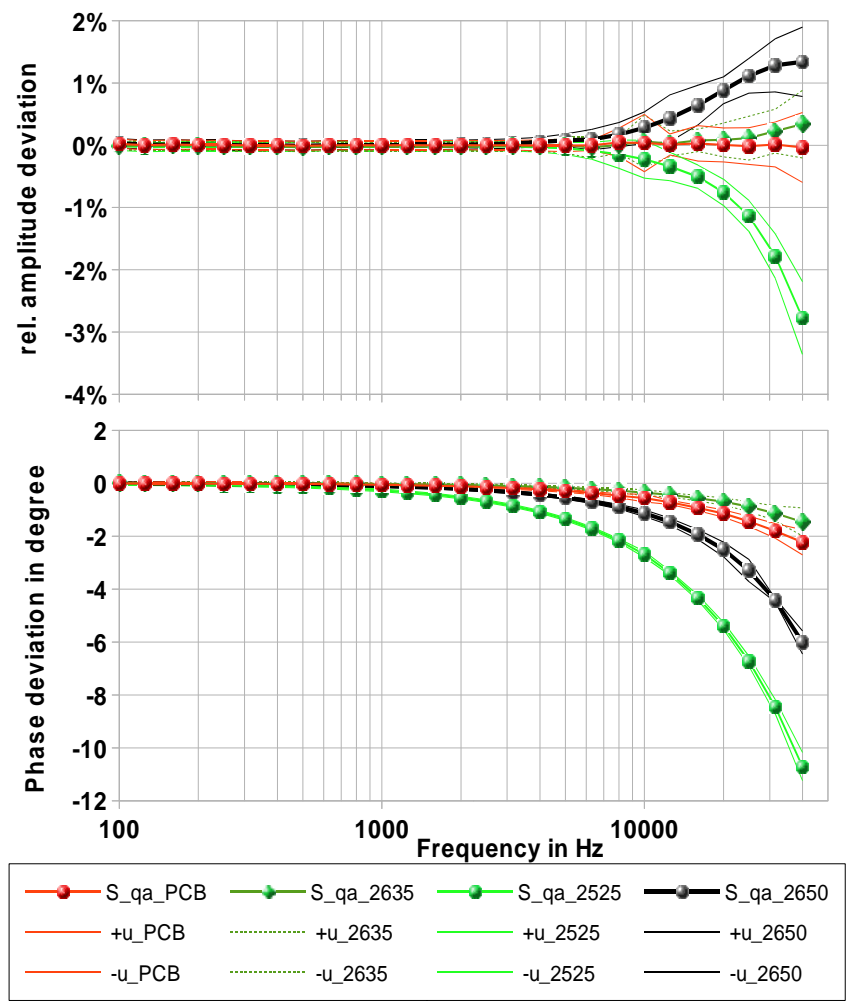

Figure 9. Amplitude and phase deviations of $S_{\mathrm{qa}}(\omega)$ with a $C_{\mathrm{s}}=248 \mathrm{pF}$ $\left(C_{\mathrm{c}}=100 \mathrm{pF}\right) \mathrm{CA}$ calibration without compensation, taking the compensated complex mean as reference.
Figure 8. Amplitude and phase deviations of $S_{\mathrm{qa}}(\omega)$ after CA compensation

taking the compensated complex mean as reference.

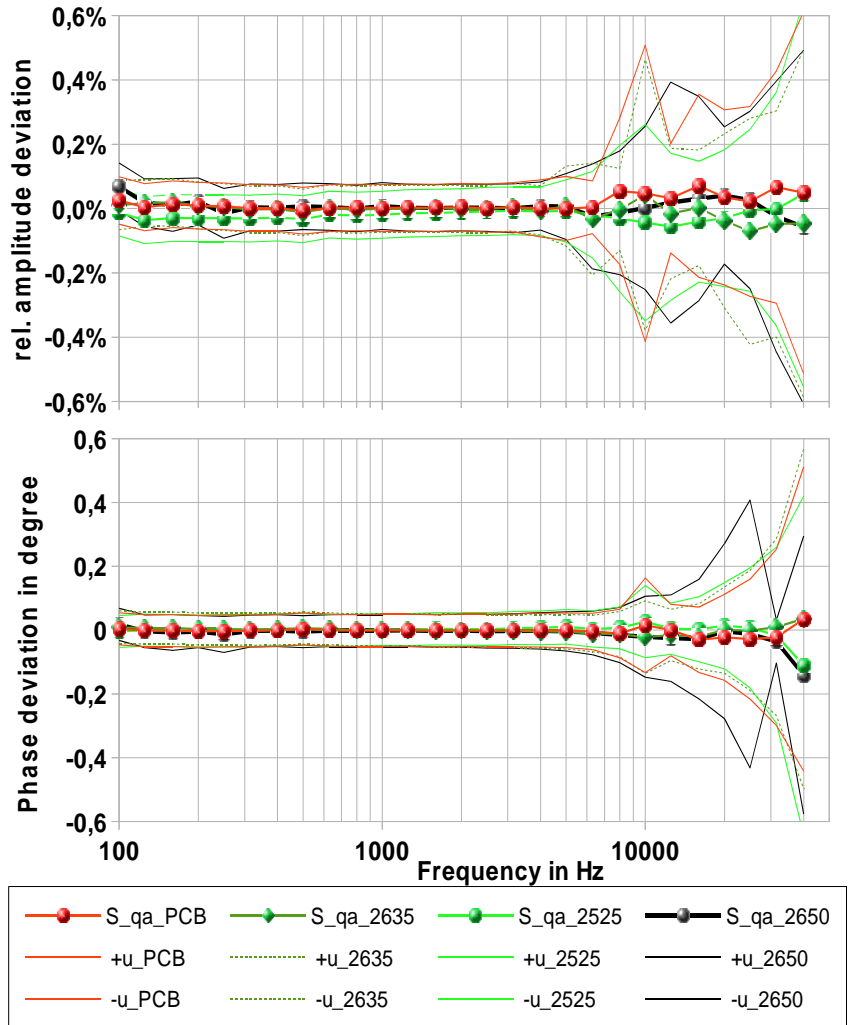




\section{REFERENCES}

[1] Schweizerische Eidgenossenschaft, Eidgenössisches Amt für Geistiges Eigentum, CH267431 (A) 1950-03-31, Messverstärker zur Messung elektrischer Ladungen,

http://worldwide.espacenet.com/publicationDetails/biblio?FT $=$ D\&date $=19500331 \& D B=E P O D O C \& l o c a l e=$ de_EP $\& C C=C$ $\mathrm{H} \& \mathrm{NR}=267431 \mathrm{~A} \& \mathrm{KC}=\mathrm{A} \& \mathrm{ND}=4$.

[2] D. Pennington, Charge Amplifier Applications, Instruments \& Control Systems, Endevco, 1965,

http://www.endevco.com/resources/tp_pdf/TP224.pdf.
[3] F. Overney, A. Rufenacht, P.P. Braun, B. Jeanneret, P.S. Wright. Characterization of metrological grade analog-to-digital converters using a programmable Josephson voltage standard, IEEE Trans. Instrum. Meas., Vol. 60, No. 7, 2011, pp. 2172-2177.

[4] G. Rietveld, C. Kramer, E. Houtzager, O. Kristensen, D. Zhao, C. de Leffe and T. Lippert, Characterization of a wideband digitizer for power measurements up to $1 \mathrm{MHz}$, Conference on Precision Electromagnetic Measurements, Daejeon, Korea, 2010, pp. 247-248. 